\title{
Constructive solutions to improve cable haulers for development of hard-to-reach cutting areas
}

\author{
F.V. Svoykin ${ }^{1}$, V.A. Sokolova ${ }^{1, *}$, N.S. Korolko ${ }^{1}$, and A.O. Shoshin ${ }^{2}$ \\ ${ }^{1}$ Saint Petersburg State Forestry University named after S.M. Kirov, 5 Institutskiy per., St. Petersburg, \\ 194021, Russia \\ ${ }^{2}$ Belarusian State Technological University, 13a Sverdlova str., Minsk, 220006, Republic of Belarus
}

\begin{abstract}
The article proposes a constructive solution for improving the technological process of logging wood with rope skidders under conditions of an extended distance of the primary haulage of wood and a considerable length of a hauling-carrying rope for hilly-ridge and waterlogged production conditions, including for selective felling (especially relevant in the Northwestern Federal District of the Russian Federation, especially in the Leningrad region, where timber harvesting in the forests of the first category predominates). The proposed solution is a double-structure carriage, obtained by connecting the mounting of the travel wheels with two articulated joints, without changing the standard designs of the existing carriages. This design allows the carriage to provide the passage of turns with a bundle of skidded timber on the curved track of the carrying rope. When introducing rope skidders with articulated carriage (SHSK), the possibility of turning the track will expand the area of the available logging fund. The use of cable scudding systems with SHSK will allow organizing skidding routes, without significant wear of the ropes, with turning angles up to 45 degrees.
\end{abstract}

In the Leningrad Region, the allowable cutting area is 8,932.9 thousand $\mathrm{m}^{3}$, with their actual use in the amount of 5,235.5 thousand $\mathrm{m}^{3}$. At the same time, tenants actually use 4 859.3 thousand $\mathrm{m}^{3}$, i.e. only $54 \%$ [1]. At the same time, the potential for using coniferous and easily accessible cutting areas is rapidly decreasing. There are more than 50 thousand water ducts in the hydrographic network of the Leningrad Region. Their total length exceeds 221 thousand $\mathrm{km}$. The indicator of specific water supply for it is 2.5 times higher than the average for the Russian Federation. Therefore, about $12 \%$ of the forest area is swamps. However, downy birch, black alder, willows, pine and spruce grow on low-lying bogs. Dense coniferous and mixed deciduous forests, interspersed with swamps, cover almost $70 \%$ of the region's territory. And it serves as an important raw material resource for the region.

In such conditions, the traditional system of machines of logging enterprises, based on heavy timber tractors with an equipped weight of 8 to 30 tons, cannot ensure the effective development of hard-to-reach cutting areas $[3,6,7]$. On swampy and waterlogged soils of

\footnotetext{
*Corresponding author: sokolova vika@inbox.ru
} 
such forests, it is possible to use machines, which during haulage exert minimum pressure on the ground. Or, when using cable haulers $(\mathrm{CH})$, exert practically no pressure.

The use of haulage methods based on mechanisms with a set of lines is the most promising on combined soils. Given this, at the Department of Technological Processes and Machines of the Forestry Complex (TP and MFC) of Saint-Petersburg State Forestry University named after S.M. Kirov, the design of a mobile cable-rail hauler (MCRH) has been developed, which makes it possible to effectively move the harvested wood in areas with waterlogged and swampy soils. However, the MCRH, developed at the level of a draft design, has significant limitations in use, namely: small value of the permissible angles of the route turn; impossibility or high degree of difficulty in overcoming sharp slopes and gullies, wide ditches, large upturned stumps, and water obstacles. On plots where there are areas with a significant swampy terrain, the laying of MCRH tracks is unprofitable, while a pack of hauled timber using cable haulers known in the forest industry reliably overcomes such areas in a suspended or semi-suspended position. In addition, it should be considered that MCRHs are not industrially produced today and will require significant costs for their creation and development $[4,5]$. Therefore, the most rational step is to improve the existing, proven cable hauling equipment for use in difficult conditions, for example, in the Leningrad region.

Usually $\mathrm{CH}$ is used for forest haulage in mountainous conditions and when it is impossible to use logging tractors. At the same time, the cutting area is developed by sectors where trees are logged, and then a running skyline is laid in the middle of the sector.

On plots with a long haulage distance, or with significant increases along the path of the pack, additional walk-through supports are installed to prevent excessive sagging of the cable, as well as to reduce dragging of timber on the ground. The devices used in this case are simple and not expensive.

However, when designing $\mathrm{CH}$, the designers did not set the task of creating rotary rope routes, since using $\mathrm{CH}$ in final cutting and selection cutting of high intensity, it is possible to set a runway, bypassing vertical obstacles. The design of the undercarriage of the bogie of well-known CHs is an $\Gamma$-shaped plate with 2-4 rollers fixed on it. This design is simple and reliable, but excludes the possibility of bending the rope in the horizontal plane and, accordingly, the possibility of turning the track. As the analysis of literary sources has shown, to this day there are no real technical proposals for the device of turns of the rope system.

Department of TP and MFC of SPbSFU named after S.M. Kirov, it is proposed to introduce carriages of a double design into $\mathrm{CH}$ system (shown in Figure 1). 


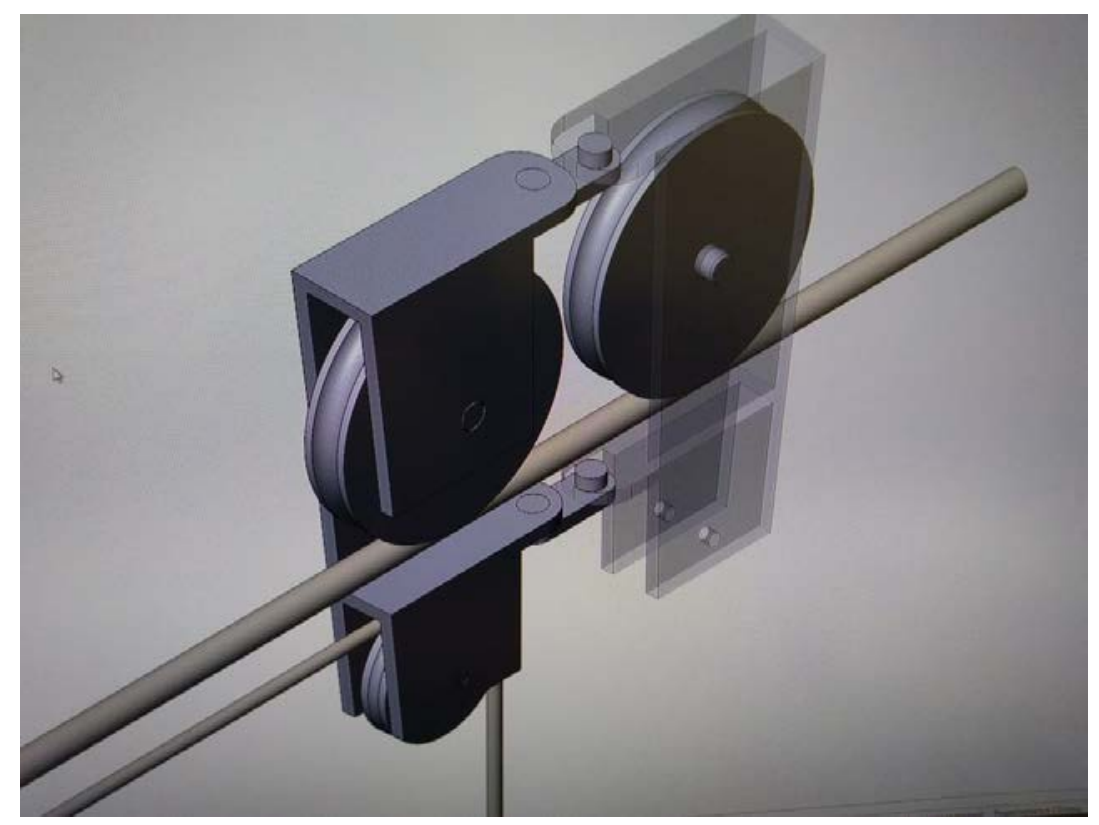

Fig. 1. $\mathrm{CH}$ carriage with double jointed wheelset.

This design allows the carriage to provide a turn-by-turn passage of a drag on a curved track of a skyline. It is proposed to use existing designs of carriages in terms of moving and lifting loads. By connecting the fastening of the travel wheels with two articulated joints, we actually get two dependent carriages moving along the skyline on one roller, which easily overcomes rope turns. Let's conditionally call such a carriage AC (articulated carriage).

With a rigidly fixed roller, it is possible to turn the track (rope) through a very limited angle. The use of a structure with rollers independent of the carriage is impossible, since the axis of the rollers must be fixed on both sides, which makes it impossible to pass at the turning point.

A significant advantage of $\mathrm{AC}$ is that its application does not require changes in the design of the existing $\mathrm{CH}$. As well as the fact that any $\mathrm{CH}$ can be equipped with a carriage of the proposed design.

The use of rotary rope routes of the skyline should become a powerful impetus for the use of $\mathrm{CH}$, since it will significantly expand the possibilities of their application. Thus, for example, considered a classic, the use of $\mathrm{CH}$ in mountainous conditions or with a new experimental application of $\mathrm{CH}$ on soils with low bearing capacities (in Belarus), the technological process is complicated by the need to harvest a large percentage of the stand during preparatory work and, in particular, when laying straight cargo runways. The equipment of $\mathrm{CH}$ has a significant weight, which limits the choice of a place for its installation with a good access. With the introduction of $\mathrm{CH}$ with $\mathrm{AC}$, the possibility of turning the route will expand the area of the available logging fund.

Promising areas of application of $\mathrm{CH}$ with AC:

- in the case of rope bends, it is possible to use the technology for the development of plots along existing paths, gaps in the forest or along ditches, which will significantly increase productivity when working on selective felling and reduce the share of manual labor, and also make it possible to develop a felling area during thaw; 
- use in protective forests or in protected areas along rivers, since the advantages of minimal damage to undergrowth, remaining stand and soil are combined with the laying of runways along river bends, around hills and other obstacles;

- The existing spreading sites require clearing of slopes and regular cleaning up of dead wood, and the delivery of equipment to places remote from the road is impossible without laying parallel transport routes. Spreading sites usually have rectilinear directions with several turns along their length. If there is a possibility of overcoming turns, it becomes possible to use $\mathrm{CH}$ for clearing spreading sites from overgrowing.

At present, a theoretical calculation of the design features of the proposed design is being carried out, including the dynamic loads arising from the inertia of the loaded carriage movement. Preliminary calculations show that the use of $\mathrm{CH}$ with AC will allow organizing haulage routes, without significant wear of the ropes, with turning angles up to 45 degrees.

\section{References}

1. Forest plan of the Leningrad region approved by the order of the Leningrad region governor No. 139- рг dated 03.03.2010, Appendix No. 6.

2. Leningrad forest. Elena Levina LesPromInform No. 7 (20), 2004. pp. 1213.https://lesprominform.ru/media/_protected/journals_pdf/1344/lesprominform_20.pdf Official website of LesPromInform (independent information and advertising publication) [Electronic resource] Accessed March 19, 2019

3. Svoykin F.V. Security (reliability) of the winter period of operation of multi-operational logging machines (harvester, forwarder) // XIII International Youth Scientific Conference 'Severgeoecotech-2012': conference proceedings (March 21-23, 2012, Ukhta): 6 hours; Part 2. - Ukhta: USTU, 2013. - pp. 256-260.

4. Svoykin F.V. Forecasting the period of logging operations at the summer logging sites of the Komi Republic // Actual problems of the development of the forest complex: materials of the international scientific and technical conference. - Vologda: VOSTU, 2013. - pp. 31-35.

5. Svoykin F.V. Improvement of technological process of timber harvesting in the conditions of the Northwestern Federal District of the Russian Federation, synopsis of a thesis, SPbSFU, 2018, 20 p.

6. Patent for utility model No. 113917 Russian Federation 'Cable-rail hauler', issued 03/10/2013, published in Bul. No. 7.

7. Patent for useful model No. 173954 Russian Federation 'Device for collecting wood with a cable-rail hauler’, issued on 21.09.2017, published in Bul. No. 27. 